\title{
En-bloc paediatric dual kidney transplantation in Hong Kong: a case series and literature review
}

YS Chan, MB, ChB, MK Yiu *, MB, BS, FHKAM (Surgery)

\author{
Division of Urology, Department of Surgery, Queen Mary Hospital, Pokfulam, Hong Kong
}

*Corresponding author: yiumk2@ha.org.hk

Hong Kong Med J 2018;24:532-4

DOI: 10.12809/hkmj166061

\section{Case series}

En-bloc paediatric dual kidney transplantation presents specific challenges but provides a viable option for patients with end-stage renal disease. In this case series, we report four cases of paediatric cadaveric en-bloc donor kidney transplantation and review the literature on reported complications and functional outcomes of this procedure.

From 2001 to 2015, there were four paediatric cadaveric en-bloc donor kidney transplantation procedures undertaken in Hong Kong. Deceased donors' mean age was $3.6 \pm 2.6$ years and recipients' mean age was $26.3 \pm 16.3$ years. Mean total operating time was $214 \pm 28.2$ minutes, mean cold ischaemic time was $222 \pm 150$ minutes, mean warm ischaemic time was $26 \pm 11.3$ minutes, and mean graft kidney volume was $156.3 \pm 31.3 \mathrm{~mL}$. The Table provides a summary of individual donor and recipient information.

The kidneys were retrieved en bloc with the donor's aorta and vena cava. The proximal end of the aorta and vena cava was oversewn at the supra-renal level and the ureters were transected as close to the bladder as possible. Recipients were prepared for extra-peritoneal implantation with modified Gibson's incision. The distal ends of the aorta and vena cava were anastomosed to the recipient's external iliac artery and external iliac vein respectively in an end- to-side manner using 5-0 Prolene (Fig). The donor ureters were anastomosed in the Wallace I manner and neocystoureterostomy was completed with 4-0 Vicryl according to the Lich-Gregoir technique with a double J stent in each ureter. ${ }^{1}$ The two graft kidneys were placed in the right iliac fossa in the extraperitoneal space created in routine kidney transplantation surgery. Two drains were placed in the surgical site.

\section{Discussion}

Historically, paediatric cadaveric kidney en-bloc donor transplantation was associated with increased early vascular complications. Furthermore, paediatric en-bloc kidneys need not be strictly allocated based on recipient weight or age criteria. ${ }^{2}$

In our series, all patients had good graft function following transplantation with normal serum creatinine levels and compensatory hypertrophy of the transplanted dual kidney occurring in all cases to overcome the size difference between the paediatric and adult kidney size. Our experience and the functional outcome achieved appear consistent with the current evidence on dual kidney transplantation in the literature.

It is well recognised that paediatric kidney transplantation is difficult, especially when donor kidneys are from children younger than 6 years of

TABLE. Summary of donor and recipient information

\begin{tabular}{|c|c|c|c|c|}
\hline & 2001 & 2009 & 2011 & 2015 \\
\hline Donor age, y & 5 & 7 & 2 & 2 \\
\hline Recipient age, y & 13 & 20 & 22 & 50 \\
\hline Donor weight, kg & 18 & 22 & 10 & 14.2 \\
\hline Recipient weight, kg & 34.8 & 53.6 & 54.8 & 78.6 \\
\hline $\begin{array}{l}\text { Recipient pathology of end-stage } \\
\text { renal disease }\end{array}$ & IgA nephropathy & $\begin{array}{c}\text { Chronic } \\
\text { glomerulonephritis }\end{array}$ & Unknown aetiology & $\begin{array}{c}\text { Diabetic } \\
\text { nephropathy }\end{array}$ \\
\hline Donor kidney volume, $\mathrm{mL}$ & 112.5 & 173.8 & 156 & 183 \\
\hline Delayed graft function & No & No & No & No \\
\hline 1-Year graft survival & Yes & Yes & Yes & Yes \\
\hline 5 -Year graft survival & Yes & Yes & Yes & Not available \\
\hline Annual graft hypertrophy rate (\%) & 1.1 & 18.4 & 20.6 & 36.2 \\
\hline
\end{tabular}




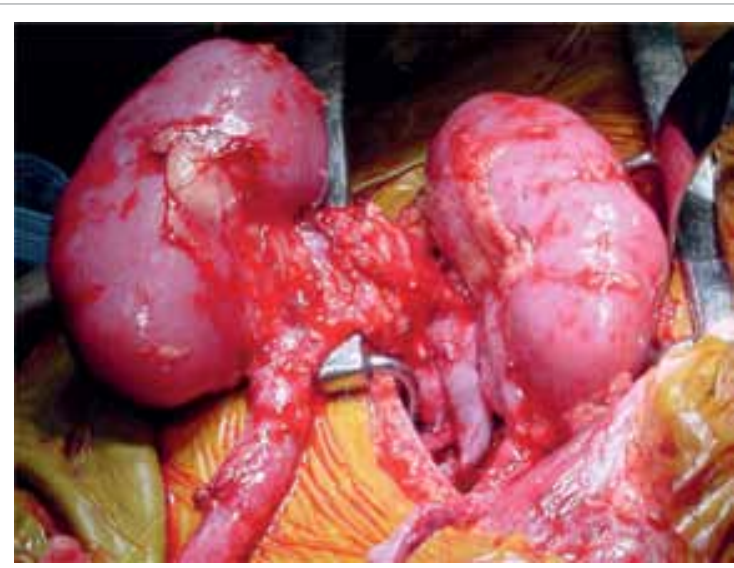

FIG. Intra-operative photograph of an en-bloc dual kidney transplantation. The proximal aortic segment was anastomosed end-to-side to the right external iliac artery and the inferior vena cava was anastomosed end-to-side to the right external iliac vein age. ${ }^{3}$ En-bloc dual kidney transplantation from paediatric donors aims to increase the nephron mass of the transplanted kidney.

En-bloc dual kidney transplantation is associated with an increase in the surgical complications rate of up to $16 \%$, of which, $69 \%$ of complications reported were arterial or venous thrombosis. ${ }^{4}$ In addition, studies have reported a higher early graft loss in the first postoperative year for paediatric en-bloc kidney transplantation. ${ }^{5,6}$ However, Thomusch et $\mathrm{al}^{5}$ reported that longterm graft survival and function were better in the paediatric dual kidney transplant than from a cadaveric adult donor.

Early graft failure is commonly caused by vascular complications. Studies have reported a vascular thrombosis rate of between $2.5 \%$ and $12 \%$ with small paediatric donor kidneys compared with a rate of $1.8 \%$ for adult donor kidneys. ${ }^{9}$ Risk factors for thrombosis include: donor less than 5 years old, ${ }^{8,10,11}$ cold ischaemic time longer than 24 hours, ${ }^{10,11}$ previous recipient transplantation, ${ }^{10}$ and increased reactive antibodies.

Although paediatric cadaveric dual kidney transplantation is associated with a higher risk of early vascular complications, paediatric donor kidneys should not be considered as marginal, as long-term graft survival and function have been shown to be superior.

When comparing the benefits of en-bloc dual kidney transplantation, a study using the Scientific Registry of Transplant Recipients registries data set has shown that for donor weight between $10 \mathrm{~kg}$ and $34 \mathrm{~kg}$, en-bloc dual kidney transplantation resulted in superior outcomes compared with single kidney transplantation. ${ }^{12}$
Another concern is the nephron mass of the transplanted paediatric kidneys. In adult cohorts, studies have shown a $43 \%$ higher risk of late graft failure for a large body surface area recipient receiving a kidney from a small donor, compared with matched-size transplantation. ${ }^{13}$ However, this finding is not relevant to paediatric donors as their kidney will undergo compensatory hypertrophy to improve function and glomerular filtration rate over time. ${ }^{14,15}$ In addition, it has been shown that increasing recipient body mass index was not a clear risk factor for poor outcome or poor graft function with small paediatric donors. ${ }^{12}$

The current evidence suggests that paediatric dual kidney transplantation is a feasible procedure, with superior long-term graft function and outcome. Therefore, paediatric dual kidney transplantation is a valuable option for patients with end-stage renal disease and paediatric cadaveric kidneys should be sourced when available.

\section{Author contributions}

All authors contributed to the concept, acquisition of data, analysis of data, drafting of the article, and critical revision of important intellectual content.

\section{Declaration}

All authors have disclosed no conflicts of interest. All authors had full access to the data, contributed to the study, approved the final version for publication, and take responsibility for its accuracy and integrity.

\section{References}

1. Moreno-Alarcón C, López-Cubillana P, López-González PÁ, et al. Lich-Gregoir technique and routine use of double J catheter as the best combination to avoid urinary complications in kidney transplantation. Transplant Proc 2014;46:167-9.

2. Hobart MG, Modlin CS, Kapoor A, et al. Transplantation of pediatric en bloc cadaver kidneys into adult recipients. Transplantation 1998;66:1689-94.

3. Fine RN. Renal transplantation of the infant and young child and the use of pediatric cadaver kidneys for transplantation in pediatric and adult recipients. Am J Kidney Dis 1988;12:1-10.

4. Snanoudj R, Rabant M, Timsit MO, et al. Donor-estimated GFR as an appropriate criterion for allocation of ECD kidneys into single or dual kidney transplantation. Am J Transplant 2009;9:2542-51.

5. Thomusch O, Tittelbach-Helmrich D, Meyer S, Drognitz $\mathrm{O}$, Pisarski P. Twenty-year graft survival and graft function analysis by a matched pair study between pediatric en bloc kidney and deceased adult donors grafts. Transplantation 2009;88:920-5.

6. Hafner-Giessauf H, Mauric A, Müller H, et al. Long-term outcome of en bloc pediatric kidney transplantation in adult recipients - up to 22 years of center experience. Ann Transplant 2013;18:101-7.

7. Sureshkumar KK, Reddy CS, Nghiem DD, Sandroni SE, Carpenter BJ. Superiority of pediatric en bloc renal allografts over living donor kidneys: a long-term functional 
study. Transplantation 2006;82:348-53.

8. Mohanka R, Basu A, Shapiro R, Kayler LK. Single versus en bloc kidney transplantation from pediatric donors less than or equal to $15 \mathrm{~kg}$. Transplantation 2008;86:264-8.

9. Kayler LK, Magliocca J, Kim RD, Howard R, Schold JD. Single kidney transplantation from young pediatric donors in the United States. Am J Transplant 2009;9:2745-51.

10. Bresnahan BA, McBride MA, Cherikh WS, Hariharan S. Risk factors for renal allograft survival from pediatric cadaver donors: an analysis of United Network for Organ sharing data. Transplantation 2001;72:256-61.

11. Singh A, Stablein D, Tejani A. Risk factors for vascular thrombosis in pediatric renal transplantation: a special report of the North American Pediatric Renal Transplant Cooperative Study. Transplantation 1997;63:1263-7.
12. Kayler LK, Zendejas I, Gregg A, Wen X. Kidney transplantation from small pediatric donors: does recipient body mass index matter? Transplantation 2012;93:4306.

13. Kasiske BL, Snyder JJ, Gilbertson D. Inadequate donor size in cadaver kidney transplantation. J Am Soc Nephrol 2002;13:2152-9.

14. Dubourg L, Cochat P, Hadj-Aïssa A, Tydén G, Berg UB. Better long-term functional adaptation to the child's size with pediatric compared to adult kidney donors. Kidney Int 2002;62:1454-60.

15. Halldorson JB, Bakthavatsalam R, Salvalaggio PR, et al. Donor-recipient size matching influences early but not late graft function after pediatric en-bloc kidney transplantation. Transplantation 2010;89:208-14. 